tion of the County of Vejle. I thank all the staff of the kitchen and the surgical ward who took part.

1 Bistrian, B R, et al, fournal of the American Medical Association, 1974, 230, 858.

${ }^{2}$ Hill, G L, et al, Lancet, 1977, 1, 689.

${ }^{3}$ Hessov, I, Acta Chirurgica Scandinavica, 1977, 143, 145.

4 Marr, J W, World Review of Nutrition and Dietetics, 1971, 13, 105

${ }^{5}$ Helms, P, Fødevaretabeller. København, Akademisk Forlag, 1973.

Requests for reprints should be addressed to: Dr Ib Hessov, Gastroenterological Department L, Kommunehospitalet, 8000 Århus C, Denmark.

(Accepted 6 February 1978)

\title{
Do brachial plexus injuries occur at initial impact in motor-cyclists?
}

Some $77 \%$ of traction injuries to the brachial plexus occur in motorcycle accidents. ${ }^{1}$ Although this injury is uncommon, amputation may be necessary when the resulting paralysis is extensive and permanent. ${ }^{23}$ The mechanism of injury has been regarded as mutual separation of the neck and shoulder as the motor-cyclist hits the ground, producing a traction injury to the plexus. ${ }^{4}$

We report here two motor-cyclists who collided head-on, with their right-hand handlebars contacting at an impact speed of about $130 \mathrm{kph}$. Both sustained severe brachial plexus injuries.

\section{The accident and the injuries}

The collision occurred on a winding country lane as the two cyclists were cutting the same corner when travelling in opposite directions (fig). Cyclist no 1 , who was fully conscious after impact, remained in the saddle and travelled a further 90 metres until he came to rest against a hedge on his left side. Cyclist no 2 was thrown to the ground after impact and was found unconscious with multiple injuries 27 metres from the site of the collision.

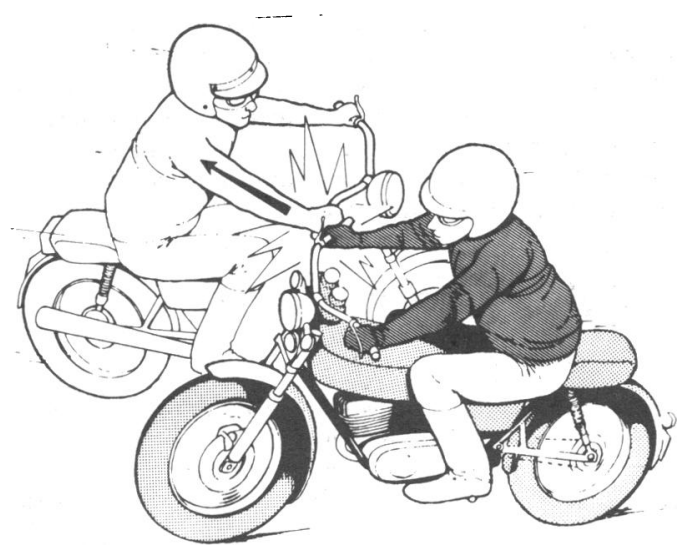

Diagram to illustrate the accident, with the mechanism of the brachial plexus injury.

The damage to both motor-cycles was consistent with a head-on handlebar collision.

On admission to hospital cyclist no 1 , aged 18, was found to have an upper brachial plexus lesion with complete loss of $\mathrm{C} 5-\mathrm{C} 8$ motor and sensory functions. There was no soft tissue or bony injury to the arm or shoulder. Findings on cervical myelography one week after injury were normal. Neurophysiological studies performed five weeks after injury suggested a widespread postganglionic brachial plexus injury affecting $\mathrm{C} 5-\mathrm{C} 8$ fibres.

On admission to hospital cyclist no 2 , aged 18 , was found to have extensive injuries to the right arm: fractures of the neck of scapula, mid-shaft of the

humerus, radius, and ulna (compound), and a complete division of the hand in the 4 th web space. There was complete loss of $C 5$ to $T 1$ motor and sensory functions. Cervical myelography ten days after injury showed pseudomeningocoeles on the right $\mathrm{C} 6,7,8$ nerve roots, suggesting traumatic avulsion of the nerve roots. ${ }^{5}$ The results of neurophysiological studies six weeks after injury were consistent with a widespread total brachial plexus injury.

Mechanism of injury-In cyclist no 1 the plexus must have been damaged at the moment of collision. The mechanism of injury was a longitudinal force $\varrho$ transmitted up the right arm from the handlebar to the shoulder, causing posterior displacement of the right shoulder and thus stretching the nerve roots and trunks close to the intervertebral foramina. This stretching of the nerves would be accentuated by the momentum of the cyclist's chest, head, $\bar{O}$ and neck, which continued to move forward. Cyclist no 2 had injuries consistent with the initial collision-the fractures being caused by a massive $\overline{\bar{c}}$ force transmitted up the arm from his hand on the handlebar; nevertheless, this mechanism remains unproved since he fell from his cycle.

\section{Discussion}

It has not been widely appreciated that in motor-cycle accidents $\vec{\omega}$ injury to the brachial plexus may occur at the time of initial impact. This might explain why Fletcher" noted a "remarkable absence of 3 actual shoulder injury and the clothing has been undamaged in this: region." With an indirect force transmitted up the arm to the shoulder $\sigma$ o girdle no direct injury takes place. If injury occurs at impact a pre- $\vec{N}$ dominance of right arm injuries would be more likely in Britain, and $\subseteq$ this has in fact been our experience.

In Newcastle we have seen a sudden increase in the incidence of severe brachial plexus injuries-six cases in eight months. Possibly the 0 increased number of motor-cycles on the road is in part responsible, $\supset$

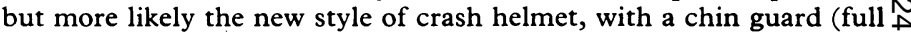
face), is responsible, partly by preserving life when a patient would $C$ have died, and partly by increasing the momentum of the head-as 5 the full face helmet is nearly twice the weight of the old jet type helmet. Sudden rotation of the handlebars may also be partly responsible and $\vec{\omega}$ this needs further investigation. Should this mechanism be sub- $\infty$ stantiated, it might be possible to incorporate an anti-jack knife mechanism into the front wheel of the cycle, thus protecting the cyclist (at least in one way) from a severely crippling injury.

We thank Mr D D Milne, consultant in charge, accident department, ฏ Newcastle General Hospital, for his help and encouragement and $\mathrm{Mr}$ 为 Hammersley, medical artist, University of Newcastle, for the figure.

1 Fletcher, I, The Hand, 1969, 1, 129.

2 Yeoman, P M, and Seddon, H J, Fournal of Bone and Foint Surgery, 1961, 43B, 493.

${ }^{3}$ Ransford, A O, and Hughes, S P F, fournal of Bone and foint Surgery, 1977, 59B, 417.

${ }^{4}$ Barnes, R, fournal of Bone and foint Surgery, 1949, 31B, 10.

5 Shapiro, R, Myelography, 3rd edn, p 195. London, Lloyd-Luke, 1975.

(Accepted 15 February 1978)

Newcastle General Hospital, Newcastle upon Tyne NE4 6BE

T ANDREW, BSC, $\mathrm{MB}$, surgical registrar

W A WALLACE, MB, FRCSED, surgical registrar (present address: orthopaedic registrar, Nottingham General Hospital)

\section{Ultraviolet light : an effective treatment of osteomalacia in malabsorption}

Intramuscular vitamin $\mathrm{D}$ has been the mainstay of treatment for osteomalacia in patients with malabsorption, as oral vitamin $\mathrm{D}$ is relatively ineffective because of poor absorption of this fat-soluble vitamin. Nevertheless, intramuscular vitamin D $B P C$ has to be given regularly in large doses and may be ineffective because of poor absorption from the injection site.

The more polar metabolites such as 25 -hydroxycholecalciferol (25-OHD) or the synthetic analogue 1- $\alpha$-hydroxycholecalciferol are more effective when given by mouth but are expensive and require extended administration and careful surveillance for hypercalcaemia. ${ }^{12}$ 